\title{
The Maxim of Order from Teachers' Perspective
}

\author{
- Ganesh Kumar Kandel
}

\begin{abstract}
This article reports the perception of teachers towards the maxim of order. It also tries to reflect the teachers' classroom behaviours or culture of teaching. It is physical reflection of their maxim that they have developed in their mind about different aspects of ELT. The researcher used classroom observation and interview as research tools. Ten teachers were the respondents in this study. These ten teachers were interviewed and three classes of each teacher were observed to obtain required information. Most of the respondents reported that they prefer calm, peaceful, ordered and disciplined classes. They provided several reasons to support their views. They expressed their positive and supporting view towards the maxim of order. The disciplined and ordered classroom is justified in this research. They argued that disciplined and ordered classroom assists the teachers to conduct their activities in comfortable way in the classroom and assists students to grasp what teacher offers them.
\end{abstract}

Key words: ELT professionals, Government-aided and privately-owned boarding schools, Maxim of order, Beliefs, Teaching culture, and Reflection

\section{Background}

Teaching is the reflection of the teachers' belief system. Different teachers have different belief system that is why we see different ways of teaching into the classroom. There is a growing body of evidences to indicate that teachers are highly influenced by their own belief systems. Borg (2001) says "Beliefs play an important role in many aspects of teaching as well as in life" (p.186). Beliefs construct about what we teach and how we teach. Borg (Ibid) defines belief as "A proposition which may be consciously or unconsciously held, is evaluative in that it is accepted as true by the individual, and therefore imbued with commitment; farther, it serves as a guide to thought and behaviour." Similarly, Wenden (1999, p. 517) says "Beliefs are viewed as individual subjective understandings, idiosyncratic aruths which are often value related and characterized by a commitment not present in knowledge..." Thus, beliefs are conceptual subjective philosophy which guides the teachers in their own path. Pajares (1992, as cited in 


\section{The Maxim of Order from Teachers' Perspective}

William \& Burden 2007 p.56) says "These had a greater influence than teachers' knowledge on the way they planned their lesson, on the kind of decision they made and on their general classroom practice."

Belief system has greater influence on ELT professionals and their classroom behaviour. Understanding teachers' belief is essential for imporving teaching practices and teacher education programmes. Classroom practices are based on the belief system. These belief systems of teachers are grounded in their personal experience and it is highly resistance to change.

The belief and thinking process underline teachers' classroom actions. Teachers' beliefs about what learning affect everything that they do in the classroom, whether these beliefs are implicit or explicit. The belief system given in William and Burden (2007, pp.57-64) are; belief about learners, beliefs about learning and teachers' belief about themselves. Similarly, Richard and Lockhart (2005, pp.32-41) mention the following beliefs: beliefs about English, beliefs about learning, beliefs about teaching, beliefs about the program and the curriculum and beliefs about language teaching as a profession. What and how the teacher presents himself/herself in the classroom is the reflection of what beliefs he/she has about learning, teaching, curriculum and professions. Teachers' individual belief system serves as the background to much of teachers' decision making and action and hence constitute the culture of teaching. Teachers' individual value system or belief system constitutes the principle of teaching or teachers' maxims in language teaching.

\section{Teachers' Maxims in Language Teaching}

Teachers' belief and value system constitute the teachers' maxims. Richard and Lockhart (1994, as given in Richard 1996, p.284) view "These beliefs and values serve as the background to much of the teachers' decision making and action and hence constitute what has been termed the culture of teaching." Following Cobuild English language dictionary, as given in Richards (1994, p.286) Maxim refers "A rule for good or sensible behavior, especially one which is in the form of a proverb or short saying." These maxims guide the teachers' actions. So, these maxims are personal working principles which reflect teachers' individual philosophies of teaching, developed from their own personal belief and value systems. Elebz (1981, in Richards 1996, p.293) talks about "Principles of practice" which corresponds with maxim. So, these maxims can also be termed as principles of practice. Anyway, teachers' maxims are personal working principles which reflect teachers' individual philosophies of teaching. These individual philosophies are developed from their experience of teaching and learning, their teacher education experiences and from their own personal belief and value system. Teachers' maxim is always personal and buttom up. These types of maxims are self guiding which are not borrowed from somebody else but evolved from persons' own beliefs or values. Different 
types of maxims are constructed on the basis of personal beliefs or value systems which are not fixed or static. That's why Maxims are dynamic and flexible rather than static of fixed.

\section{Types of Teachers' Maxims}

There are several types of teachers' maxims given in Richards (1996, pp.287-292) which are as follows:

- The Maxim of Involvement: This maxim follows the learners' interest to maintain students' involvement.

- The Maxim of Planning: This maxim allows the teacher to plan their teaching and try to follow it. Regarding this Woods in Richards (1996, p.289) says "For the teacher, the preplanned curriculum was the central in her thinking."

- The Maxim of Encouragement: This maxim seeks ways to encourage students learning. There is informal relationship between teacher and students. Regarding this, Tsui (1995, p. 357) comments "Students did not have to stand up to great him, and they didn't have to raise their hands or stand up and there was a lot more laughter."

- The Maxim of Order: The teacher, who follows this maxim, maintains order and discipline througut out the lesson. Richards (1996, pp.289-290) exemplifies a secondary level female teacher whose class is considered as one of the best in the school because of the students' academic result and their well disciplined behaviour. She conducted her class in somewhat formal teacher-centered manner and judged her lessons as effective according to whether they accomplished what was planned and achieved their learning outcomes. This maxim is in favours of formal relationship between teachers and students and prioritizes for formal teacher-centered classroom rather than student-centered classroom.

\section{The Study}

The maxim of order is being followed by so many teachers in our context. It is against recently developed student centered methods. Teachers are quite familiar that the classroom should be much democratic and interactive to ensure the maximum participation of students in teaching learning activities. But they are found doing their activities with help of loud unpleasant voice and strong command regarding what to do and what not to do in the classroom. Moreover, teachers are often found controlling class with the help of stick or corporal punishment. Why are they doing so even if being much familiar with other maxims which are corresponded with new approach and methods. It was urgently realized to research the teachers' perception towards the maxim of order. The study was carried out to seek the answers of the following questions:

- What are teachers' perceptions towards the maxim of order?

- What are teachers' classroom behaviour (culture of teaching) in terms of ordered and 


\section{The Maxim of Order from Teachers' Perspective}

disciplined classroom, class controlling strategies, students' and teachers' role and relationship in the class, teaching methods and students' participation in teaching learning process?

- What may be the pedagogical implications of the study?

The English language teachers of secondary level teaching in both government-aided schools and privately-owned boarding schools were the population of my study. I purposively selected five government-aided and five privately-ownedsecondary level boarding schools of Surkhet district. I selected one teacher from each school purposively and got interview with them taking the help of recording device. I observed three classes of each selected teachers of governmentaided and privately-owned secondary level boarding schools after taking permission for the classroom observation. The research helped to understand the teachers' perception and their classroom behaviours with the help of the interview and classroom observation checklist.

\section{Analysis and Interpretation}

Qualitative analysis was used in this study because it is useful where:

- Little is known about the research area.

- Richer understanding is sought.

- More in-depth information is needed.

- There are already existing sources such as diaries, students' assignments, video recording, and reports.(Norton 2009, p.116)

Teachers' maxim is an abstract concept. Teachers' classroom behaviour is the reflection of such maxims. It is needed to collect the in-depth information of such abstract concept. So I collected various information about teachers' perception towards the maxim of order. The data were collected from interview and classroom observation checklist. I used qualitative approach to analyze and interpret data. Different headings and sub-headings were created to interpret the information. I presented the direct quotation of speech of the interviewee as the evidence data for the qualitative research. I made the interpretation of findings through triangulation of the data collected from two sources: interview and observation checklist. 


\section{Result}

\section{Classroom Observation Holistic Data}

Table No. 1

\begin{tabular}{|c|c|c|c|}
\hline Item/Scale & Yes $(\%)$ & No $(\%)$ & Remarks \\
\hline \multicolumn{4}{|l|}{ 1. Maintenance of order and discipline } \\
\hline i. Maintains peaceful and calm environment thoughtout the lesson & $90 \%$ & $10 \%$ & \\
\hline ii. Behaves in an authoritative way & $80 \%$ & $20 \%$ & \\
\hline iii. Neglects students' questions & - & $100 \%$ & \\
\hline iv. Discourages interaction in classroom & $20 \%$ & $80 \%$ & \\
\hline v. Judges the students' activities carefully & $70 \%$ & $30 \%$ & \\
\hline \multicolumn{4}{|l|}{ 2. Strategies applied to control the classroom } \\
\hline i. Scolds to students & $50 \%$ & $50 \%$ & \\
\hline ii. Uses sticks in the classroom & $10 \%$ & $90 \%$ & \\
\hline iii. Gives order to students & $70 \%$ & $30 \%$ & \\
\hline iv. Tells jokes, stories etc to students & $30 \%$ & $70 \%$ & \\
\hline v. Gives some tasks to students & $40 \%$ & $60 \%$ & \\
\hline vi. Involves students into different activities & $20 \%$ & $80 \%$ & \\
\hline vii. Humiliates student who speaks in the classroom & $30 \%$ & $70 \%$ & \\
\hline \multicolumn{4}{|l|}{ 3. Role in the classroom } \\
\hline i. Students as an active participant & $30 \%$ & $70 \%$ & \\
\hline ii. Students as passive listener & $70 \%$ & $30 \%$ & \\
\hline iii. Teacher as facilitator & $20 \%$ & $80 \%$ & \\
\hline iv. Teacher as an authoritative power & $80 \%$ & $20 \%$ & \\
\hline v. Other roles & - & $100 \%$ & \\
\hline \multicolumn{4}{|l|}{ 4. Teaching Methods } \\
\hline i. GT method & $30 \%$ & $70 \%$ & \\
\hline ii. Direct method & $50 \%$ & $50 \%$ & \\
\hline iii. Audio- lingual method & - & $100 \%$ & \\
\hline iv. Communicative method & $10 \%$ & $90 \%$ & \\
\hline v. Other methods & $10 \%$ & $90 \%$ & \\
\hline \multicolumn{4}{|l|}{ 5. Teacher's relationship with students } \\
\hline i. Knows all students' name & $70 \%$ & $30 \%$ & \\
\hline ii. Gives attention to an individual & $10 \%$ & $90 \%$ & \\
\hline iii. Asks personal matter of students & $20 \%$ & $80 \%$ & \\
\hline iv. Students feel easy while talking with teacher & $50 \%$ & $50 \%$ & \\
\hline v. Students ask unnecessary questions & - & $100 \%$ & \\
\hline vi. Students feel relaxed in the classroom & $20 \%$ & $80 \%$ & \\
\hline vii. Students talk frequently with teacher & $20 \%$ & $80 \%$ & \\
\hline viii. Teacher smiles before starting the lesson & $40 \%$ & $60 \%$ & \\
\hline
\end{tabular}




\begin{tabular}{|ll|c|c|c|}
\hline \multicolumn{1}{|c|}{ Item/Scale } & Yes (\%) & No (\%) & Remarks \\
\hline 6. & Students participation in teaching learning process & & & \\
\hline i. & Students' participation in group and pair work & - & $100 \%$ & \\
ii. & Students' ownership in learning & $30 \%$ & $70 \%$ & \\
iii. & Encourages students to interact in the classroom & $50 \%$ & $50 \%$ & \\
iv. & Delivers all content in one way & $50 \%$ & $50 \%$ & \\
v. & Asks several questions to students & $70 \%$ & $30 \%$ & \\
vi. & Encourages students to share their ideas, feeling and experiences & $20 \%$ & $80 \%$ & \\
\hline
\end{tabular}

Six main items including thirty five sub-items were observed to find out the teachers' classroom behaviour/culture of teaching in the classroom. These types of teachers' classroom behaviours were the reflection of his/her belief system and maxims. The above given table shows that most of the teachers' maintained order and discipline throughout the lesson. In order to maintain ordered and disciplined classroom, they behaved in an authoritative way discoursing interaction in the classroom. Students were found being passive listener. Teachers were found maintaining order and discipline in the classroom giving order and threaten to students. Most of the teachers were found using teacher centered method and not providing individual care to students. Surpringly, I found only few teachers encouraging students to share ideas, experience and feelings. All of the above mentioned teachers whether they were from government-aided or privately -owned boarding schools showed their positive attitude towards the maxim of order which had been reflected in their classroom behaviour/way of teaching in the classroom

\section{Interview with Teachers}

I got interview to collect the feeling, experiences and perceived attitudes of the English language teachers towards the maxim of order. I took their perception and views on different aspects and analyzed according keeping them into different key points.

\section{Key point 1: Maintenance of order and discipline}

Almost all the teachers expressed their attitude in favour of ordered and disciplined classroom.

\section{Key point 2: Class controlling strategies}

Almost all the teachers opined that they follow different class controlling strategies to maintain ordered and disciplined classroom.

\section{Key point 3: Classroom environment}

Most of the teachers accepted that calm and peaceful environment was very much important in ELT classroom. They argued that calm and peaceful environment is essential for both effective teaching and meaningful learning. 


\section{Key point 4: Students' talking in the classroom}

Most of the teacher expressed their attitude against students talking into the classroom. Only difference was that some of them expressed their views directly where as some expressed indirectly against students' talking in the class.

\section{Key point 5: Relationship with students}

Most of the teachers(7 out of 10) expressed their view in favours of formal relationship with students.

\section{Key point 6: Group and pair work}

All the teachers argued that they conducted group and pair work in the classroom.

\section{Key point 7: Different ELT Methods}

Majority of the teachers opined their view in favour of GT and Direct method.

\section{Key point 8: Students' role in the classroom}

Most of the teachers ( 8 out of 10) expressed that their students played the role of active participant in the classroom.

\section{Key point 9: Respect and Greeting from students}

Almost all the teachers (except 1) replied that they wanted to be respected and greeted from their students.

\section{Key point 10: Teachers as all in all in the class}

Most of the teachers ( 9 out of 10) rejected their role as all in all in the classroom. They argued that teachers (They) were also learners.

The above depicted teachers' response on different aspects shows that the teachers are in favours of maxim of order. It is justified that teachers enjoy ordered and disciplined classroom.

\section{Discussions of Findings}

Through the triangulation of research tools, information is taken from the respondents. The findings are derived after cross-checking of information obtained through interview and classroom observation. Most of the teachers were found very much positive and in favours of maxim of order. Many of them preferred giving order to the students to keep peaceful and calm environment in their classes. They were found playing the role of authoritative power in the classroom even if they expressed quite contrasting opinions in their interview. All most all of them enjoyed keeping formal relationship in the classes with students. Most of them seemed preferring traditional teacher-centered method even if their opinions on interview were different. Most of them expressed their opinions in favours of group and pair work. 


\section{The Maxim of Order from Teachers' Perspective}

But none of them were found doing so in their classes which was actually realized while observing their classes. Teachers were not found giving individual attention to the students. Most of the teachers accepted their role as facilitator in the interview but just opposite role was found playing by them im my classroom observation. Only $20 \%$ of the teachers were found in the role of facilitator in their classroom. They argued that they were not all in all in their classroom. They supposed themselves as learners in interview. But surprisingly, their role was of all in all in the classroom which was actually realized while observing their classroom.

\section{Conclusion}

Teachers' maxims are reflected in their teaching behaviours. These teaching behaviours should develop the ownership of learning on thepart of students. Learners' autonomy is today's buzz words in the ear of each ELT professionals. The teaching learning process is assumed to be targeted towards achieving learners' autonomy. Through my study, it is obvious that most of teachers prefer the maxim of order which is identified through classroom observation and interview with them. Teachers feel comfortable into the peaceful and calm environment inside the classroom. They appreciate well-mannered and disciplined classroom where they can play the role of all in all in the classes. It is noteworthy fact that teachers should change themselves and try their best to involve their students into different activities. It is essential to involve students into different activities such as group work, pair work, project work and so on to ensure the feeling of autonomy on the part of learners while learning language. The maxim of involvement and encouragement seem to be much effective. So, it is better if teachers guide their activities keeping these maxims in their mind. The scolding, threatening and sometimes the corporal punishment given to students are better to be excluded as far as possible which the teachers use to maintain ordered and disciplined classes. Instead of such activities, teachers can engage students to do something which really fills their mind and soul with fun, excitement and laughter.

\section{References}

Borg, M. (2001).Teachers' beliefs. ELTJournals. Vol. 55. pp. 168-188.

Norton, L. S. (2009). Action research in teaching and learning: A practical guide to conducting pedagogical research in universities. London and NewYork: Rutledge.

Richards, J. C. (1996). Teachers' maxims in language teaching.TESOL quarterly.Vol. 30. pp. 281-295.

Richards, J. C., \& Lockhart, C. (2005). Reflection teaching in second language classroom. Cambridge : CUP.

Richards et al. (2001). 'Exploring teachers' belief and process of change'. The APA jounal.Vol. 1. pp.41-62. 